\title{
Prevalence of iodine deficiency among pregnant women in Gwembe and Sinazongwe districts of Southern Province, Zambia: a cross-sectional study
}

\author{
Trevor Kaile ${ }^{1 *} \mathbb{D}$, Bornwell Sikateyo ${ }^{2}$, Masauso M. Phiri ${ }^{1}$ and Charles Michelo ${ }^{3}$
}

\begin{abstract}
Background: Maternal iodine deficiency is one of the common causes of morbidity and mortality during pregnancy. Maternal iodine deficiency during pregnancy is associated with a number of adverse outcomes such as abortion, stillbirth, congenital anomalies, perinatal mortality and irreversible mental retardation. A study conducted in Zambia among pregnant women in 2013 on the prevalence of iodine deficiency showed that iodine deficiency was not a public health concern. The previous study used Urine lodine concentration (UIC) as a marker of iodine deficiency among the pregnant women. Our study was conducted to assess the prevalence of iodine deficiency among pregnant women in Gwembe and Sinazongwe districts of Southern Province, Zambia, using urine iodine concentration and goitre presence by manual palpation.
\end{abstract}

Methods: We carried out a community based, cross sectional study in rural areas of Gwembe and Sinazongwe districts between April 2016 to March 2018. Data were collected from 412 pregnant women by a multistage cluster sampling technique. The presence of a goitre was examined by manual palpation and urinary iodine concentration was determined by the Ultra Violet Method using PerkinElmer Labda UV Spectrometer equipment made in Jena Germany (Model 107,745). As part of the existing baseline data, we used results of a 2013 countrywide study $(n=$ 489) for household salt iodine content which showed a greater than $40 \mathrm{ppm}$ at $76.2 \%$, between 15 and $40 \mathrm{ppm}$ at $19.21 \%$ and less than $15 \mathrm{ppm}$ at 4.59\%. Statistical analysis was done using Stata version 14.0. The outputs of analysis are presented as median and Interquartile range (IQR) as the urine data were not normally distributed. Further, the categorical and independent variables were presented as proportions (percentages) to describe the distribution and trends in the target sample population.

(Continued on next page)

\footnotetext{
* Correspondence: tkaile89@yahoo.co.uk

'Department of Pathology and Microbiology, The University of Zambia, Ridgeway Campus, Lusaka, Zambia

Full list of author information is available at the end of the article
}

C C The Author(s). 2020 Open Access This article is licensed under a Creative Commons Attribution 4.0 International License, which permits use, sharing, adaptation, distribution and reproduction in any medium or format, as long as you give appropriate credit to the original author(s) and the source, provide a link to the Creative Commons licence, and indicate if changes were made. The images or other third party material in this article are included in the article's Creative Commons licence, unless indicated otherwise in a credit line to the material. If material is not included in the article's Creative Commons licence and your intended use is not permitted by statutory regulation or exceeds the permitted use, you will need to obtain permission directly from the copyright holder. To view a copy of this licence, visit http://creativecommons.org/licenses/by/4.0/ The Creative Commons Public Domain Dedication waiver (http://creativecommons.org/publicdomain/zero/1.0/) applies to the data made available in this article, unless otherwise stated in a credit line to the data. 


\begin{abstract}
(Continued from previous page)
Results: The median Urine lodine concentration (UIC) of the pregnant women was $150 \mu \mathrm{g} / \mathrm{L}$ (Interquartile Range (IQR): 100-200 $\mathrm{\mu g} / \mathrm{L}$ ). Based on the UIC, There were 49\% pregnant women who had inadequate iodine intake with urine iodine concentration of less than $150 \mu \mathrm{g} / \mathrm{L}, 34.0 \%$ had UIC of $150-249 \mu \mathrm{g} / \mathrm{L}$ indicating adequate iodine intake, $13.0 \%$ with UIC of $250-499 \mu \mathrm{g} / \mathrm{L}$ indicating more than adequate iodine intake, and $5.0 \%$ with UIC of above $500 \mu \mathrm{g} / \mathrm{L}$ indicating excessive iodine intake. To determine whether the women had access to iodized salt, we used baseline data from 2013 Zambia national survey for iodine concentration in household salt samples as being an average of 40 ppm, which also showed that $95.41 \%$ households consumed adequately iodized salt ( $\geq 15 \mathrm{ppm})$. The prevalence of goitre in our study was very low at $0.02 \%$ among the pregnant women of all ages who participated in the study (18-49years).

Conclusion: lodine deficiency was still not a public health concern among the pregnant women of Gwembe and Sinazongwe districts of Southern Province in Zambia. Goitre prevalence has remained very low in this study area. The UIC and goitre observations were consistent with the Zambia National Food and Nutrition Commission findings in 2013 report. However, our study showed more pregnant women with insufficient than adequate iodine status indicating the risk of developing IDD is still high in this region. It also reinforces the argument that strengthening of the existing salt iodization program is needed in order to make a homogenous iodated salt available to the communities. The National Food and Nutrition Commission of Zambia needs to find innovative ways of sensitizing people about the adverse effects of IDDs and how these could be prevented. It is recommended that iodine supplementation be introduced as part of the package of Antenatal clinic care for all pregnant women.
\end{abstract}

Keywords: Pregnant women, lodine, Urine iodine, lodine deficiency, Goitre, lodization of salt

\section{Background}

Iodine is an essential micronutrient used by the body to synthesize thyroid hormones that are necessary for normal growth, development and metabolism [1-3]. Low iodine intake results in inadequate production of thyroid hormones that results in a syndrome known as iodine deficiency disorders (IDD) [4].

Iodine deficiency (ID) is a global health problem regardless of the level of development of the country $[4,5]$. It was estimated in 2011 that 1.8 billion people consumed inadequate iodine and were at risk of developing IDD [6]. The most vulnerable from the consequences of ID were pregnant women and their new born babies. The results of iodine deficiency are abortion, still birth, mental retardation of children born from such mothers, low birth weight, perinatal death, stunted infant growth, neuromotor, intellectual, behavioural and cognitive impairments, neonatal hypothyroidism and goitre [7-14]. WHO stated that the most prevalent cause of brain damage but yet preventable disorder was iodine deficiency $[15,16]$. There is paucity of data on the prevalence of iodine deficiency in pregnancy in Zambia.

Iodine Deficiency Disorders had been a great public health concern in Zambia leading to a number of prevalence studies [17-22]. A goitre prevalence of $38 \%$ was reported among children in Serenje District in Central Province as far back as 1951 [18]. This was followed by a nationwide comprehensive survey on IDD that involved 37 Districts from 8 provinces using goitre detected by neck palpation as a maker of iodine deficiency in 1971 . The study found a goitre prevalence of $50.5 \%$ with a range from 27 to $81 \%$ across the whole country [18]. In
1989, a survey involving, 1163 children aged between 3 and 14 years in Livingstone in the Southern Province recorded a goitre prevalence of 18\% [19]. In 1991, another survey observed a goitre prevalence of $68 \%$ in 105 pupils aged between 8 and 12 years in Choma in Southern Zambia [19]. A United Nations Children's Fund (UNICEF) survey involving 2505 pupils drawn from all the nine provinces of Zambia recorded a goitre prevalence ranging from 9 to $82 \%$ with a mean of $31.6 \%$ across the country [20]. A 2011 IDD impact survey showed a marked stride in improving adequate iodine status in the population with an IDD prevalence of $14 \%$ using mid urine iodine concentration [21].

The 2013 survey conducted among pregnant women showed that ID was not a public health concern [14]. However, no study has been conducted to simultaneously assess prevalence of ID among pregnant women in rural Zambia after reinforcement of monitoring of iodized salt imported into Zambia 1998. Gwembe and Sinazongwe districts of Southern Province in Zambia were among the high prevalence areas for Iodine deficiency in surveys done before 2011.

Therefore, this study was conducted to assess the prevalence of Iodine deficiency in pregnant women in Gwembe and Sinazongwe districts of Southern Province in Zambia as a way of determining the effectiveness of iodine intake among the pregnant women in Zambian population.

\section{Methods}

\section{Study design}

This was a community based, cross-sectional, quantitative study with both descriptive and analytic elements. 


\section{Study setting}

The study was conducted between April 2016 to March 2018 in 6 and 12 Census Supervisory Areas (CSA) of Gwembe and Sinazongwe respectively. A Census Supervisory Areas is a lowest census unit in Zambia containing at least $80-120$ households in a rural area and 120-150 households in an urban area with an average of 6 family members per household.

\section{Sample size}

A single proportion sample size calculation formula was used to determine optimal sample size for estimating the prevalence of iodine deficiency. A sample size of 412 pregnant women was computed based on an estimated 32\% prevalence of goitre in 1998 in the same area. In 2011, the nationwide survey showed $26.4 \%$ prevalence of UIC $<150$ $\mu \mathrm{g} / \mathrm{L}$ [15], at $95 \%$ confidence level, $5 \%$ margin of error, design effect of 1.5 and non response rate of $10 \%$. In this cross sectional study, our response rate was a $100 \%$.

\section{Sampling technique}

A convenient sampling was used to select the pregnant women from the rural health centre catchment areas on first-come-first-recruitment basis using the census supervisory areas (CSA). The women were recruited as they came for their antenatal assessments. The pregnant women were identified as they came to the clinic by Rural Health centre staff (nurses, midwives and Medical Assistants). Individual participants were then selected using a systematic approach.

\section{Data collection method}

In the surveys, data were collected using a pre-tested structured questionnaire. Socio-demographic data were collected using questions adapted from the Demographic and Health Surveys (DHS) questionnaire [19]. The questionnaire was prepared in English and translated into local language (Chitonga). It was administered in either/ both languages according to participant preference. Data were collected by trained Rural Health Centre staff (nurses, Midwives, Medical Assistants and clinical Laboratory staff).

\section{Goitre examination}

Presence of goitre was examined by trained and experienced clinic staff using manual palpation techniques and graded according to the criteria of WHO/UNICEF/ ICCIDD [2]. The goitre was then classified as, grade 0 (no goitre), 1 (Palpable but not visible goitre) and grade 2 (palpable and visible goitre).

\section{Urine sample collection and laboratory analysis}

Random urine samples were collected from every 10th pregnant woman in disposable plastic cup specimen containers and transferred into screw capped plastic vials. Vials were sealed with parafilm to prevent leakage and evaporation. They were transported to Lusaka, University of Zambia, School of Medicine Laboratory where the urine samples were frozen and stored at $-20^{\circ}$ $\mathrm{C}$ until they were analysed at the Food and Drugs laboratory in Lusaka, Zambia. Urine Iodine Concentration (UIC) was measured in duplicate by Ultra Violet Method using PerkinElmer Labda UV Spectrometer equipment, Jena, Germany. The UIC was categorized according to $\mathrm{WHO} / \mathrm{UNICEF} / \mathrm{ICCIDD}$ recommended epidemiological criteria for assessing iodine intake in pregnant women. Accordingly, the UIC was categorized as less than $150 \mu \mathrm{g} / \mathrm{L}, 150-249 \mu \mathrm{g} / \mathrm{L}, 250-499 \mu \mathrm{g} / \mathrm{L}$, and equal and greater than $500 \mu \mathrm{g} / \mathrm{L}$. [2]

\section{Data analysis}

The data was analysed using Strata SE v.40. Histograms and the Kolmogorov-Simmov test were used to check for normality of numeric data before further analysis. Descriptive analysis was done using median and interquartile range (IQR) and percentage as appropriate for categorical and continuous variables. UIC was skewed and not normally distributed. Non-parametric MannWhitney $\mathrm{U}$ test and Wallis test were used to compare the median UIC and salt iodine concentration and differences between groups of categorical independent variables.

Bivariate and multivariate logistic regression analyses were used to identify the variables associated with goitre status. Independent variables were selected and included in the analysis to observe their effects on the development of goitre. In multivariate logistic regression analyses was undertaken to identify risk and predisposing factors to the development of goitre. These factors were; maternal education, and awareness of iodized salt and IDD, maternal age, parity, gestational age and salt iodine level.

\section{Results \\ Study participants characteristics}

This is shown in Tables 1 and 2 as Population distribution and characteristics of study participants in Rural Gwembe and Sinazongwe districts, Southern Province, Zambia, April 2016 - March 2018. They were almost four times more participants from Sinazongwe than Gwembe districts. All the 412 pregnant women were recruited as participants in their third trimester. The median age of the participants was 21.1 years but above 18 years of age. The legal age of consent for study participation is 18 years in Zambia. This could explain why there were no women below the age of 18 years participating in the study. The majority of the pregnant women were primagravidae (63\%), Gestational age at recruitment was third trimester for 412 women (100\%). 
Table 1 Site population and age distribution data of the study participants

\begin{tabular}{lll}
\hline Site & \multicolumn{2}{l}{ Number of Respondents } \\
Gwembe & $153(23.2 \%)$ & \\
Sinazongwe & $479(75.8 \%)$ & \\
Total & $632(100 \%)$ & Sinazongwe \\
& Age distribution (in years) \\
Age & Gwembe & $270(56 \%)$ \\
Less than 20 & $84(59 \%)$ & $138(29 \%)$ \\
$20-25$ & $35(24 \%)$ & $32(7 \%)$ \\
$26-30$ & $7(5 \%)$ & $23(5 \%)$ \\
$31-35$ & $9(6 \%)$ & $12(3 \%)$ \\
$36-40$ & $7(5 \%)$ & $4(1 \%)$ \\
More than 40 & $1(0.7 \%)$ & 479 \\
Totals & 143 & \\
\hline
\end{tabular}

The median number of pregnancies was 1 . Of these women, $10 \%$ were illiterate, $49 \%$ had primary education, $41 \%$ had secondary education. Prevalence of goitre $(0.02 \%)$, which was very low, was not associated with age, parity, lack of basic education, employment status, consumption of sorghum or sources of water.

The pregnant women in our study were mainly subsistence farmers $(64 \%)$ who grow only enough food for their families. They consumed mostly maize $(92 \%)$, the regional staple food, although a few grew and consumed sorghum as well.

The water sources that were available to these participants were safe water from either borehole or tap water (77\%). By contrast, only about $23 \%$ used the alternative sources from rivers, streams and wells. The average family size was $\operatorname{six}(+/-2)$.

Table 2 Study population education levels and parity

\begin{tabular}{lll}
\hline & \multicolumn{2}{l}{ Educational profiles } \\
Education & Gwembe & Sinazongwe \\
None & $31(22 \%)$ & $42(9 \%)$ \\
Primary & $71(50 \%)$ & $234(49 \%)$ \\
Junior High School & $35(24 \%)$ & $131(27 \%)$ \\
Senior High School & $6(4 \%)$ & $66(14 \%)$ \\
Totals & 143 & 479 \\
Parity & Parity & \\
More than 1 & Gwembe & Sinazongwe \\
1 & $24(17 \%)$ & $78(16 \%)$ \\
0 & $20(14 \%)$ & $104(22 \%)$ \\
Totals & $99(69 \%)$ & $297(62 \%)$ \\
\hline
\end{tabular}

\section{Occupation status, food and water sources}

The majority of the women were farmers who grew enough of their own food, mainly maize, to feed their families. The main source of water for their daily use was borehole water which did not have iodine added to it.

\section{Knowledge of iodised salt and iodine deficiency disorders and practice of use of iodized salt}

More than $80 \%$ of the participants indicated that they had heard about iodized salt through radio campaigns (NFNC). Other sources of information were Community Health workers $(\mathrm{CHW})$. Iodized salt usage in our study was $96 \%$ of the women iodized coarse salt and $1.6 \%$ fine iodised salt.

\section{Desk review on iodine concentration of household salt samples $(n=489,2013)$}

The review data of iodine concentrations (ppm) in the salt samples from households ranged from less than 15 to above $40 \mathrm{ppm}$. Adequately iodated salt with 15-40 ppm iodine was $19.21 \%$, iodine content less than $15 \mathrm{ppm}$ was $4.59 \%$ and above $40 \mathrm{ppm}$ was $76.2 \%$ [14].

The UIC was tabulated according to the WHO /UNICEF/ICCIDD criteria. The table showed the median UIC in third trimester as $150 \mu \mathrm{g} / \mathrm{L}$ (IQR: $100-200 \mu \mathrm{g} / \mathrm{L}$ ). There were $49 \%$ pregnant women who had inadequate iodine intake with urine iodine concentration of less than $150 \mu \mathrm{g} / \mathrm{L}, 34.0 \%$ had UIC of $150-249 \mu \mathrm{g} / \mathrm{L}$ indicating adequate iodine intake, $13.0 \%$ with UIC of $250-499 \mu \mathrm{g} / \mathrm{L}$ indicating more than adequate iodine intake, and $5.0 \%$ with UIC of above $500 \mu \mathrm{g} / \mathrm{L}$ indicating excessive iodine intake,.

\section{Prevalence of goitre}

Figures 1 and 2 showed the trend of goitre prevalence over time in the different towns and districts in Zambia. It is shown that the prevalence of goitre among the pregnant women in Gwembe and Sinazongwe districts study area was $0.02 \%$ (only 1 woman out of 412 had a palpable goitre) this was grade 1 goitre. There was no visible grade 2 goitre among the pregnant women who participated in the study. The trend shows that there was a significant reduction of goitre in the population from 1951 to 2018.

\section{Discussion}

The study findings concurs with the observations of 2011 and 2013 countrywide survey that reported that Iodine deficiency was no longer a public health concern in Zambia. This was confirmed by use of both clinical signs for the presence of goitre in pregnant women as well as biochemical methods of determining random urine iodine concentration. The goitre prevalence was very low at $0.02 \%$ and Urinary Iodine concentration median at $150 \mu \mathrm{g} / \mathrm{L}$, with an interquartile range of 100 


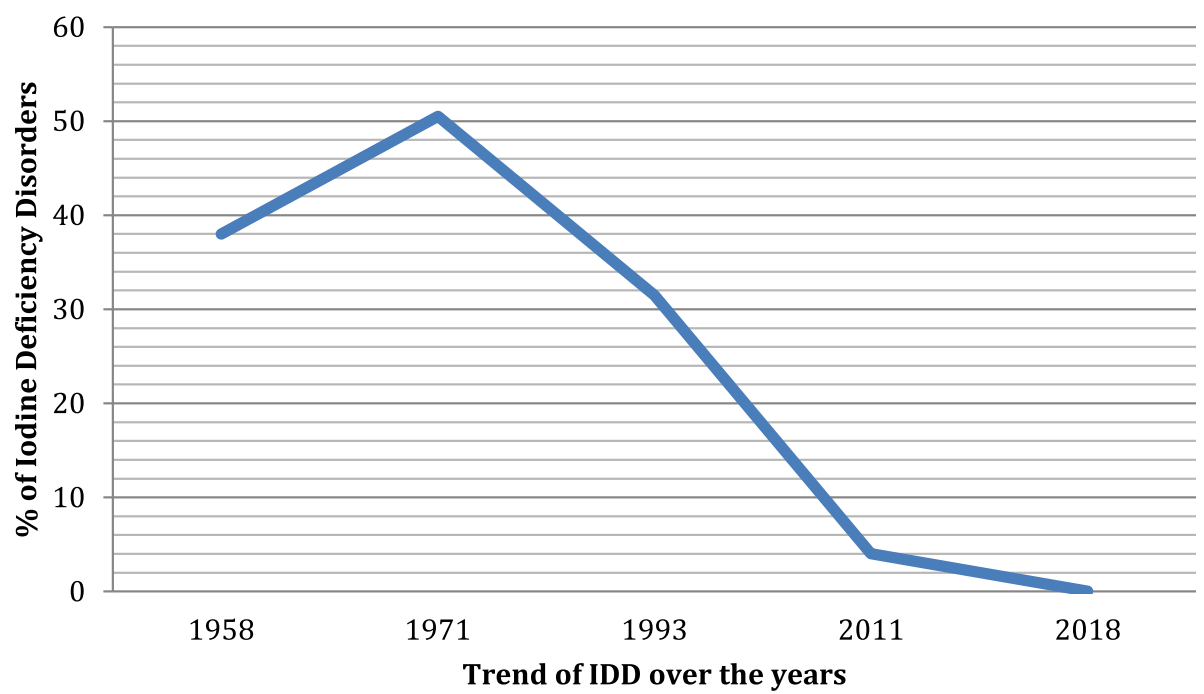

Fig. 1 The prevalence of iodine deficiency over the years

$200 \mu \mathrm{g} / \mathrm{L}$. The urinary iodine concentrations represents recent iodine intake and could be used as a good indicator of iodine status [23]. It has been observed that prevalence of goitre tended to increase in women of multiparity [14, 21, 22, 24], who were of older age group, although age by itself did not have much effect except for women who had repeated pregnancies [24]. This trend was not observed in our study as the majorityThe majority of the pregnant women were primagravidaes and below the age of 25 years $(77 \%)$ as a result could be less at risk of goitre (Tables 1 and 2).

Studies carried out in Denmark, France and Turkey all showed that illiteracy among pregnant women and guardians was associated with predisposition to Iodine deficiency in pregnant women and school going age
[25-30]. The explanation given is that was that educated women with disposable income tended to afford iodated salt and that they had enough knowledge on the importance of consumption of iodated salt. However, multivariate analysis of our data did not show any link between goitre development and maternal literacy levels (Tables 1 and 2), this was demonstrated by the very low goitre prevalence observed in the study communities (Figs. 1 and 2) with a significant down ward trend since goitre monitoring started in Zambia.

In Table 3, the iodine Urine concentrated were grouped according to the WHO/UNICEF/ICCIDD criteria. We observed a median UIC of $150 \mu \mathrm{g} / \mathrm{L}$ in $34 \%$ of the pregnant women. This was within the range of $150-249 \mu \mathrm{g} / \mathrm{L}$ which was indicative of iodine sufficiency or adequate iodine

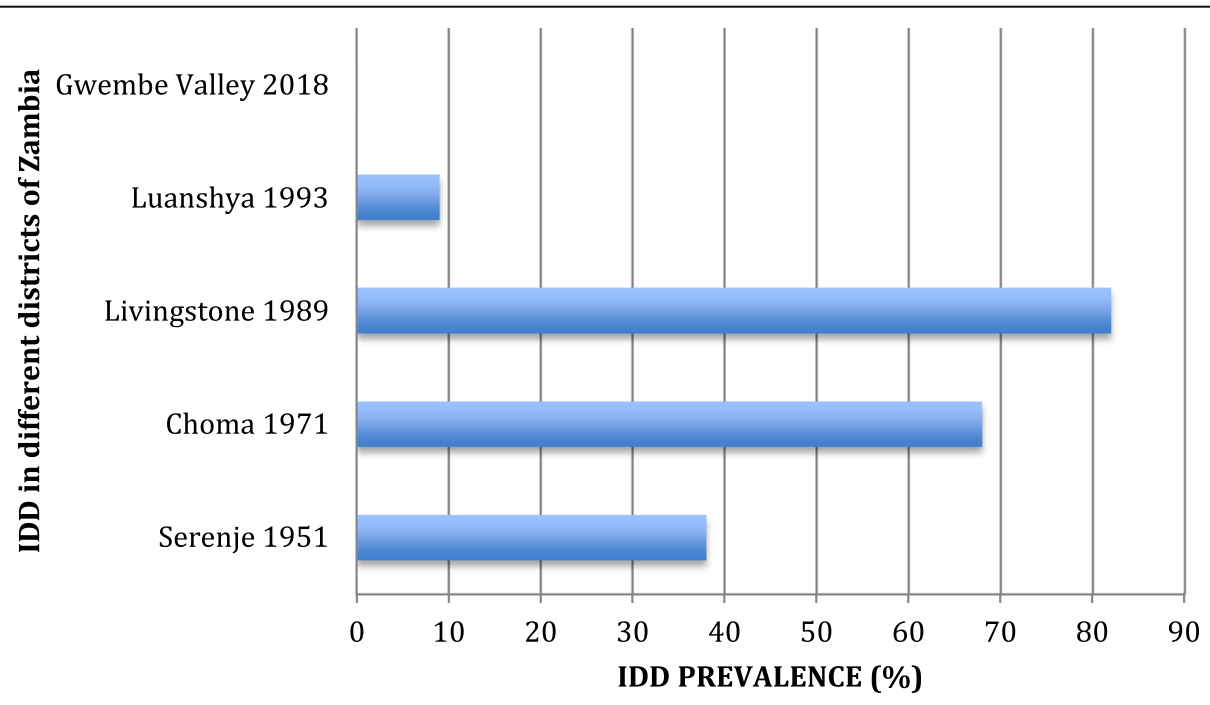

Fig. 2 The IDD prevalence in different districts of Zambia since the start of IDD monitoring 
Table 3 Urinary iodine concentration levels in pregnant women in their third trimester in Gwembe and Sinazongwe of Southern Province, Zambia from April 2016 to March $2018(n=218)$

\begin{tabular}{llll}
\hline lodine intake status & $\begin{array}{l}\text { Urine lodine } \\
\text { concentration }(\boldsymbol{\mu g} / \mathbf{L})\end{array}$ & Number $(\mathbf{n})$ & Percent $(\%)$ \\
\hline Insufficient & $<150$ & 106 & 48.6 \\
Adequate & $150-249$ & 74 & 34.0 \\
More than Adequate & $250-499$ & 28 & 12.8 \\
Excessive & $\geq 500$ & 10 & 4.6 \\
Total & & 218 & 100 \\
\hline
\end{tabular}

intake in line with WHO/UNICEF/ICCIDD criteria [2]. In this study the median UIC was $150 \mu \mathrm{g} / \mathrm{L}$, which was within the recommended adequate minimum median UIC for pregnant women. However, in Table 3, 49\% of our study participants had insufficient recommended UIC (< $150 \mu \mathrm{g} / \mathrm{L}$ ) which was below the cut off for adequate iodine intake. This is almost half of the study participants showing iodine intake lower than the recommended minimum median UIC for pregnant women which suggests that half of the pregnant women and their new born may still suffer from adverse effects of iodine deficiency in Gwembe and Sinazongwe districts.

Our study results are in contrast to the previous study carried out to determine the iodine status of pregnant women in Zambia of 2011. This study reported a prevalence of Iodine deficiency with UIC less $150 \mu \mathrm{g} / \mathrm{L}$ at $26.4 \%$ [14] and a median UIC of $264 \mu \mathrm{g} / \mathrm{L}$ which was above the normal range of $150-249 \mu \mathrm{g} / \mathrm{L}$. [14] This study also reported a normal median UIC of $150 \mu \mathrm{g} / \mathrm{L}$ but which was negatively skewed. We observed a reduction on the median UIC in the current study suggesting a relaxation on monitoring of consumed iodated salt in the communities. This suggests that the pregnant women were still at risk of IDD thus predisposing their new borns also to IDD.

The WHO/UNICEF/ICCIDD criteria for prevalence of goitre greater than $5 \%$ indicated a public health problem [2]. The prevalence of goitre in the current study was $0.02 \%$ which was far much lower than the cut off where IDD would be considered a public health problem. The prevalence was far lower in these areas and suggests a consistent downward trend of the goitre through out the country as shown in (Figs. 1 and 2). The overall reduction in whole country may be an indication that the iodine supplementation strategies put in place by the National Food and Nutrition Commission of the Republic of Zambia are yielding results and a continuous monitoring of imported salts for human and animal consumption should be strengthened (NFNC). However with an increase in insufficient iodine intake status and a reduction in iodine status for adequate iodine intake by the pregnant women shown in Table 3, the IDD problem may still resurface in Zambia. This finding is significant and we propose that the National Food and Nutrition Commission needs to reinforce monitoring and compliance of salt iodization and other iodine fortification and supplementation in other food staffs. The observed increase in iodine concentration in salt samples used by households may help in mitigating increased iodine intake [27].

The pregnant women in our study were mainly farmers $(64 \%)$ who grew enough food for their families. Further, these families grew and consumed mostly maize (92\%), the regional staple food, although a few grew and consumed sorghum as well. Maize consumption did not predispose to iodine deficiency. This observation suggested good nutrition status for the study population.

The water sources that were available to these participants were safe water from either borehole or tap water (77\%). By contrast, only about $23 \%$ used the alternative sources from rivers, streams and wells. Sources of water were not associated with goitre or inadequate iodine intake.

It is now universally accepted that universal salt iodization (USI) consisting of iodizing all salt meant for human and animal consumption is the most affordable way of alleviating IDD [2]. The National Food and Nutrition Commission of Zambia of 2013 found 19.21\% of household salt sample to be using adequately iodated salt (15-40 ppm iodine), 4.59\% (at less than $15 \mathrm{ppm}$ ) and $76.2 \%$ (at above $40 \mathrm{ppm}$ ). This showed that most salt manufacturers were complying with iodization of salt process, although most them were over iodizing the salt [27]. This observation of high iodine in salt may be desirable considering that almost half (49\%) of the pregnant women had less that $150 \mu \mathrm{g} / \mathrm{L}$ of median UIC meaning that they were not taking enough iodine in their daily consumption hence higher iodine levels in household salt was a better strategy of increasing iodine status in pregnant women. This study findings reinforces the suggestion that poor adherence to salt regulation by salt producers requires continuous effective monitoring system at ports of entry for all imported and locally produced salt in Zambia. The improvement of effective coverage of adequately iodated salt by manufacturers through effective monitoring would assist in mitigating insufficient and excessive iodine intake among pregnant 
women in Zambia. The low iodine status among women suggests that there is a lack of knowledge about IDD and consumption of iodised salt among pregnant women in Gwembe and Sinazongwe districts implying that dissemination of IDD and its effects on the foetus has not been conveyed comprehensively at consumer community level.

To the best of our knowledge, this is the second study in Zambia to assess the prevalence of goitre among pregnant women using clinical and biochemical methods. This study had some limitations in that a single random sample of urine was collected for analysis of iodine. Urinary iodine tended to have a daily variation depending on individual iodine intake of each woman. Therefore urinary iodine concentration could only be used to assess the iodine status of a population but not of individuals [23]. Micronutrients such as selenium that was known to enhance iodine deficiency were not measured in our study. The other limitation was that we depended on baseline data from National Food and Nutrition Commission of Zambia for household iodine content in salt. We did not measure iodine content of water and other food staffs. Inter individual variations may have occurred among the clinical staff when palpations for goitre were done. Ultrasound detection of goitre may be more sensitive but may not be practicable in low resource settings like Zambia.

\section{Conclusion}

Iodine deficiency was still not a public health concern among the pregnant women of Gwembe and Sinazongwe districts of Southern Province in Zambia. Goitre prevalence has remained very low in this study area. The UIC and goitre observations were in line with the Zambia National Food and Nutrition commission findings of 2013 report. However, our study showed more pregnant women with insufficient than adequate iodine status indicating a risk to developing IDD is still high in this region. It also reinforces the argument that strengthening of the existing salt iodization program is needed in order to make a homogenous iodated salt available to the communities. The National Food and Nutrition Commission of Zambia needed to find innovative ways of sensitizing people about the adverse effects of IDDs and how these could be prevented. It is recommended that iodine supplementation be introduced as part of the package of Antenatal clinic care for all pregnant women.

\footnotetext{
Abbreviations

NHDS: National Health Demographic survey; FAO: Food and Agricultural Organization; ICCIDD: International Council on Control of lodine Deficiency Disorders; IDD: lodine Deficiency Disorders; UIC: Urinary lodine

Concentration; USI: Universal salt iodization; WHO: World Health Organization

Acknowledgments

We would like to thank the District Nursing Officers; Ms. Maggie Mukuta, and Ms. Jestina Kafunga for the logistics assistance in collecting data and samples
}

from the participants as well as Professors V. S. Singaram and R. Hift from University of KwaZulu Natal as study leaders for the first author.

\section{Authors' contributions}

TK conceived the study, designed the study, oversaw the data collection, analysed the data and drafted the manuscript; BS assisted in statistical analysis of the data and participated in the drafting of the manuscript; MMP assisted in drafting manuscript and editing and CM participated in the drafting and editing of the manuscript. All authors have read and approved the manuscript.

\section{Funding}

We would like to acknowledge the financial support provided by the Norwegian Agency for Development (NORAD) through the NORHED QZA0848 QZA-MW-13/00032, The USA NIH through the MEPI grant and SACORE Grant, All the funders did not influence or participate in the design of the study, collection, analysis, and interpretation of data and in writing the manuscript.

\section{Availability of data and materials}

Data and materials availability for this manuscript can be requested from the corresponding author in reasonable time.

Ethics approval and consent to participate

Ethical clearance was obtained from the institutional review boards of University of Zambia Biomedical Research Ethics Committee (FWA 00000338, IRB 00001131 Ref. No. 003-05-02) and University of KwaZulu-Natal (FWA 678, Rec 290408-009, Ref: 131/14). Approval was given by Ministry of Health to carry out the study $(\mathrm{MH} / 101 / 17 / 6)$. The local authorities of the districts were informed about the study objectives and they participated in logistics. After the study purpose was explained to the pregnant women informed written consent was obtained. Confidentiality of the data obtained from participants was strictly secured and maintained.

\section{Consent for publication}

Not applicable.

\section{Competing interests}

We have no competing interests.

\section{Author details}

'Department of Pathology and Microbiology, The University of Zambia, Ridgeway Campus, Lusaka, Zambia. ${ }^{2}$ Department of Medical Education Development, The University of Zambia, School of Medicine, Ridgeway Campus, Lusaka, Zambia. ${ }^{3}$ The University of Zambia, School of Public Health, Ridgeway Campus, Lusaka, Zambia.

Received: 23 April 2020 Accepted: 9 November 2020

Published online: 09 December 2020

\section{References}

1. Andersson M, Takkouche B, Egli I, Benoist B. The WHO global database on iodine deficiency disorders: the importance of monitoring iodine nutrition. Scand J Nutr. 2003:47(4):162-6.

2. FAO/WHO. Vitamin and mineral requirements in human nutrition. 2nd ed. Geneva: World Health Organization; 2004.

3. WHO/UNICEF/ICCIDD. Assessment of iodine deficiency disorders and monitoring their elimination: A guide for program managers. 3rd ed. Geneva: World Health Organization; 2007.

4. Zimmermann MB, Jooste PL, Pandav CS. lodine-deficiency disorders. Lancet. 2008;372(9645):1251-62.

5. Pearce EN, Andersson M, Zimmermann MB. Global iodine nutrition:where do we stand in 2013? Thyroid. 2013:23:523-8.

6. Andersson M, Karumbunathan V, Zimmermann MB. Global iodine status in 2011 and trends over the past decade. J Nutr. 2012;142:744-50.

7. Glinoer D. The importance of iodine nutrition during pregnancy. Public Health Nutr. 2007:10:1542-6.

8. Yadav K, Pandav CS. National Iodine Deficiency Disorders Control Programme: current status \& future strategy. Indian J Med Res. 2018; 148(5):503. 
9. WHO/UNICEF/ICCIDD. Assessment of iodine deficiency disorders and monitoring their elimination: a guide for programme managers. MANUAL; 2007.

10. Delange F. The disorders induced by iodine deficiency. Thyroid. 1994;4(1): 107-28.

11. Delange F, Bürgi H. lodine deficiency disorders in Europe. Bull World Health Organ. 1989;67(3):317.

12. Nawoor Z, Burns R, Smith D, Sheehan S, O'herlihy C, Smyth P. lodine intake in pregnancy in Ireland_a cause for concern? Ir J Med Sci. 2006;175(2):21.

13. Pharoah P, Buttfield I, Hetzel B. Neurological damage to the fetus resulting from severe iodine deficiency during pregnancy. Int J Epidemiol. 2012;41(3): 589-92.

14. Pharoah P, Connolly K. A controlled trial of lodinated oil for the prevention of endemic cretinism: a long-term follow-up. Int J Epidemiol. 1987:16(1):68-73.

15. Smyth P, O'Herlihy C. Dietary iodine intake in pregnancy. Irish Med J. 2006; 99(4):103.

16. Trumpff C, Schepper JD, Tafforeau J, Van Oyen H, Vanderfaeillie J, Vandevijvere S. Mild iodine deficiency in pregnancy in Europe and its consequences for cognitive and psychomotor development of children: a review. J Trace Elem Med Biol. 2013;27(3):174-83.

17. NFNC. lodine deficiency disorders (IDD) impact survey 2002: IDD indicators Lusaka Zambia: The National Food and Nutrition Commission (NFNC) of Zambia; 2003. www.nfnc.org.zm.

18. Nwokolo U. Endemic goitre in Zambia. J Trop Med Hygiene. 1974;77(10): 233-8.

19. Lumbwe CM. Goiter prevalence among school children in Choma; 1991.

20. Lumbwe CM. Iodine deficiency in Zambia. Lusaka, Zambia: National Food and Nutrition Commission; UNICEF; 1995.

21. NFNC. lodine deficiency disorders (IDD) impact survey 2011. Lusaka, Zambia: The National Food and nutrition commission (NFNC) of Zambia; UNIICEF; 2011.

22. Office CS. 2010 census of population and housing Zambia - population summary report. Lusaka, Zambia: Central Statistical Office; 2012.

23. Konig F, Andersson M, Hotz KAl, Zimmermann MB. Ten repeat collections for urinary iodine from spot samples or 24-hour samples are needed to reliably estimate individual iodine status in women. J Nutr. 2011;141:2049-54

24. Pharoah P, Buttfield I, Hetzel B. The effect of iodine prophylaxis on the incidence of endemic cretinism. Adv Exp Med Biol. 1972;30:201-21.

25. Skeaff SA. Assessing iodine intakes in pregnancy and strategies for improvement. J Trace Elem Med Biol. 2012;26(2-3):141-4.

26. Pandav CS, Yadav K, Srivastava R, Pandav R, Karmarkar M. lodine deficiency disorders (IDD) control in India. Indian J Med Res. 2013;138(3):418.

27. NFNC. The status of iodine deficiency among pregnant women in Zambia: iodine deficiency survey report. Lusaka, Zambia: The National Food and Nutrition Commission of Zambia; 2013. www.nfnc.org.zm.

28. Valeix P, Faure P, Peneau S, Estaquio C, Hercberg S, Bertrais S. Lifestyle factors related to iodine intakes in French adults. Public Health Nutr. 2009; 12(12):2428-37.

29. Knudsen N, Bulow I, Laurberg P, Ovesen L, Perrild H, Jørgensen T. Low socio economic status and familial occurrence of goitre are associated with a high prevalence of goiter. Eur J Epidemiol. 2003;18(2):175-81.

30. Gür E, Ercan O, Can G, Akkus S, Guzeloz S, Ciftcili S, Arvas A, Iltera O. Prevalence and risk factors of iodine deficiency among school children. Trop Pediatr J. 2003;49(3):168-71.

\section{Publisher's Note}

Springer Nature remains neutral with regard to jurisdictional claims in published maps and institutional affiliations.

Ready to submit your research? Choose BMC and benefit from:

- fast, convenient online submission

- thorough peer review by experienced researchers in your field

- rapid publication on acceptance

- support for research data, including large and complex data types

- gold Open Access which fosters wider collaboration and increased citations

- maximum visibility for your research: over $100 \mathrm{M}$ website views per year

At $\mathrm{BMC}$, research is always in progress.

Learn more biomedcentral.com/submissions 